\title{
Case Report: Leprosy Osteoarticular Alterations Mimicking Rheumatoid Arthritis
}

\author{
Rachel Bertolani do Espírito Santo, ${ }^{1,2}$ Rachel A. Serafim, ${ }^{1,2}$ Jurama Barros Gueiros Bitran, ${ }^{3}$ Simon M. Collin, ${ }^{4}$ and \\ Patrícia Deps ${ }^{1 \star}$ \\ ${ }^{1}$ Department of Social Medicine, Federal University of Espírito Santo, Vitória, Brazil; ${ }^{2}$ Faculdade Brasileira de Vitória - Multivix Vitória, Vitória, Brazil; \\ ${ }^{3}$ Hospital Universitário Cassiano Antônio de Moraes, Universidade Federal do Espírito Santo, Vitória, Brazil; ${ }^{4}$ National Infection Service, Public \\ Health England, London, United Kingdom
}

\begin{abstract}
Deformities of bones of the face and extremities are markers of leprosy (Hansen's disease) which contribute to stigma associated with this disease. Among these deformities are articular alterations that can mimic rheumatoid arthritis (RA). In this case, a 64-year-old man presented with a history of having been treated for lepromatous leprosy and erythema nodosum leprosum episodes, which evolved with joint alterations similar to those of RA. Most cases of leprosyrelated arthritis are associated with reactional episodes, of which a large number do not respond to conventional therapy for leprosy reactions. In cases of chronic arthritis not associated with leprosy reactions, although patients show considerable relief with anti-leprosy therapy, arthritis is not completely resolved. This emphasizes the need for early diagnosis and treatment of leprosy to prevent the development of osteoarticular alterations.
\end{abstract}

\section{INTRODUCTION}

Leprosy is a chronic infectious and contagious disease caused by Mycobacterium leprae and Mycobacterium lepromatosis bacilli. ${ }^{1,2}$ In addition to affecting the skin, peripheral nerves, and multiple internal organs, it can also affect nasal tissues and bones. ${ }^{3,4}$ The disease exhibits a broad spectrum of clinical forms, with manifestations varying between the tuberculoid and lepromatous poles. ${ }^{5}$ Alterations of the facial skeleton and of the limbs are historical markers of leprosy and part of the stigma of this disease. Leprosy remains a serious health problem, causing permanent disabilities and deformities. ${ }^{6}$ Among these deformities are articular alterations that can mimic rheumatoid arthritis (RA). ${ }^{7-12}$

\section{CASE DESCRIPTION}

A 64-year-old African-American man, working as a security guard, was diagnosed with lepromatous leprosy in 1965 and was compulsorily admitted to a colony hospital in Brazil. Medical records show that he was initially treated exclusively with sulfone. Ten years later, he was treated with dapsone, and in 1983, he received multidrug therapy (MDT) according to WHO recommendations for multibacillary leprosy. He was considered cured after 2 years of treatment. Medical records indicated several episodes of erythema nodosum leprosum (type 2 leprosy reaction) before, during, and after MDT. Thalidomide was administered on all occasions. At the time of this case report (2016), the patient was suffering from systemic arterial hypertension and depression and was being treated with amlodipine, propranolol, and clonazepam.

Physical examination showed nasal septum perforation, saddle nose deformation, joint deformities mimicking RA with synovitis of proximal interphalangeal and metacarpophalangeal joints in both hands (Figure $1 \mathrm{~A}$ and $\mathrm{B}$ ), and reduced range of motion in the proximal and distal interphalangeal joints of the hands and feet. The hands and feet showed a loss of sensation with preserved strength. The feet exhibited a deformity known as "claw toes" or "hammer toes" (Figure 2). Laboratory tests for

*Address correspondence to Patrícia Deps, Department of Social Medicine, Federal University of Espírito Santo, Av. Marechal Campos, 1468 Maruípe, Vitória 29047-105, Brazil. E-mail: patricia.deps@ ufes.br rheumatoid factor, C-reactive protein, and antinuclear factor were all unreactive; the erythrocyte sedimentation rate was $5 \mathrm{~mm} / \mathrm{hr}$, calcium $8.7 \mathrm{mg} / \mathrm{dL}$, and uric acid $4.5 \mathrm{mg} / \mathrm{dL}$.
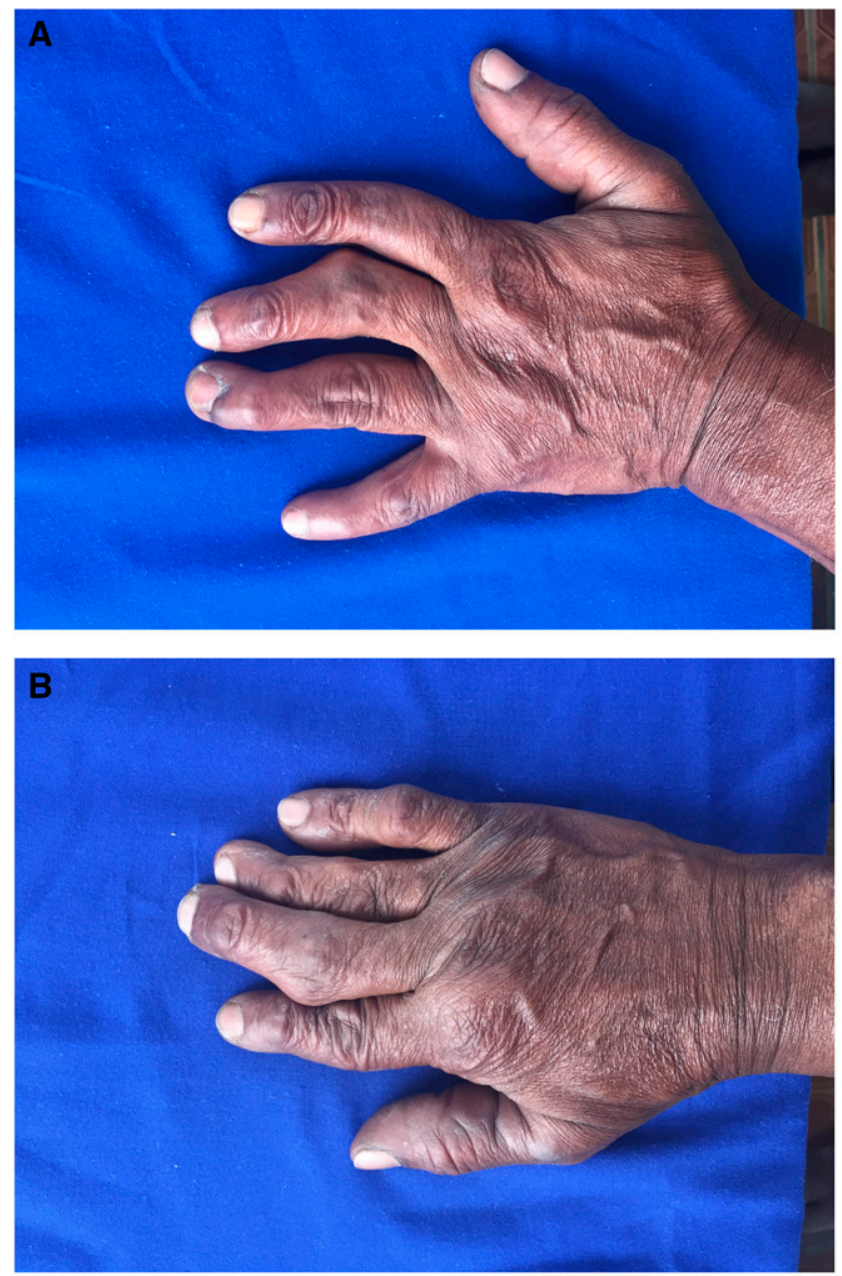

FIGURE 1. (A) Left hand showing: joint deformities mimicking rheumatoid arthritis (RA), with synovitis of the proximal interphalangeal and metacarpophalangeal joints. (B) Right hand showing: joint deformities mimicking RA, with synovitis of the proximal interphalangeal and metacarpophalangeal joints. This figure appears in color at www. ajtmh.org. 


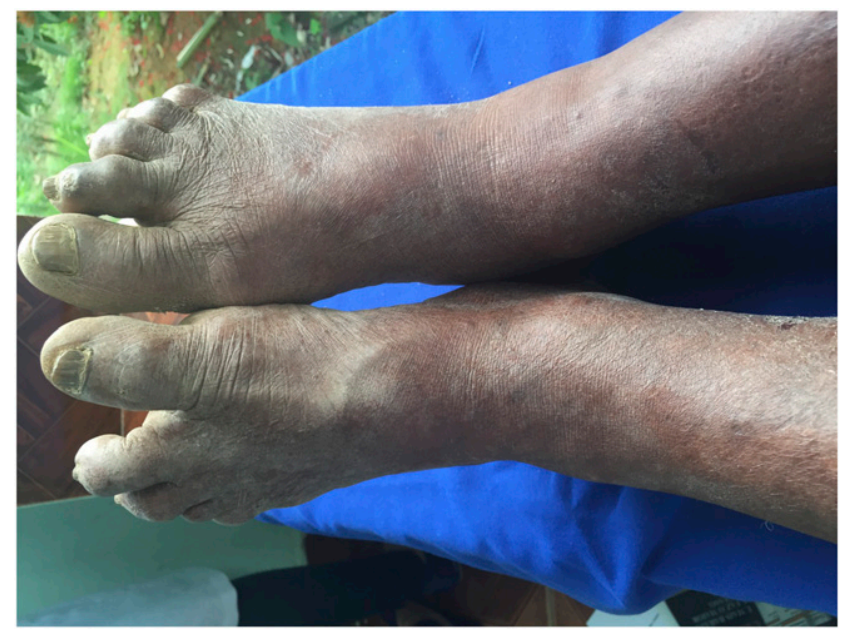

FIGURE 2. Feet: joint deformities mimicking rheumatoid arthritis ("hammer toes"). This figure appears in color at www.ajtmh.org.

Radiography of the hands showed reduction of the metacarpophalangeal joint spaces of the second and third bilateral fingers and reduction of the interphalangeal joint spaces from the second to the fifth finger associated with subchondral sclerosis. This was more pronounced in the proximal interphalangeal joints, where deformity with marginal osteophytosis, sparse subchondral cysts, and subluxation was observed with ulnar deviation from the second to the fifth bilateral finger (Figure 3). In the right hand, a "boutonnière" deformity in the fifth finger and a "swan neck" in the third finger were observed. In the left hand, a "swan neck" deformity from the third to the fifth finger and a "mallet finger" deformity of the second bilateral finger were observed (Figure 4).

Radiography of the feet showed reduction of the metatarsophalangeal joint space of the bilateral hallux and interphalangeal joint associated with subchondral sclerosis of the articular surfaces, marginal osteophytosis, and subchondral cysts (Figure 5). Medial phalangeal flexion and hyperextension of the distal phalanges, most evident in the

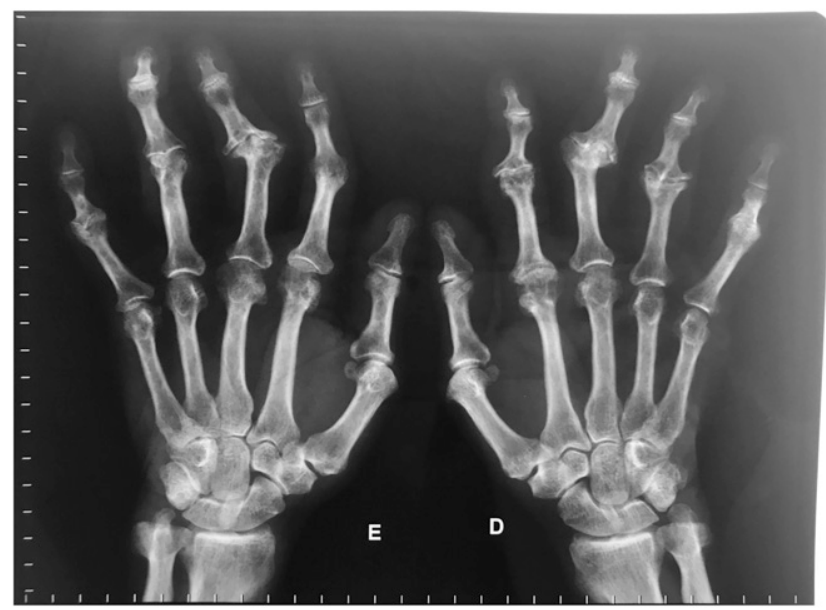

FIGURE 3. Reduction of metacarpophalangeal and interphalangeal joint spaces. Marginal osteophytosis, sparse subchondral cysts, and subluxation in the proximal interphalangeal joints.

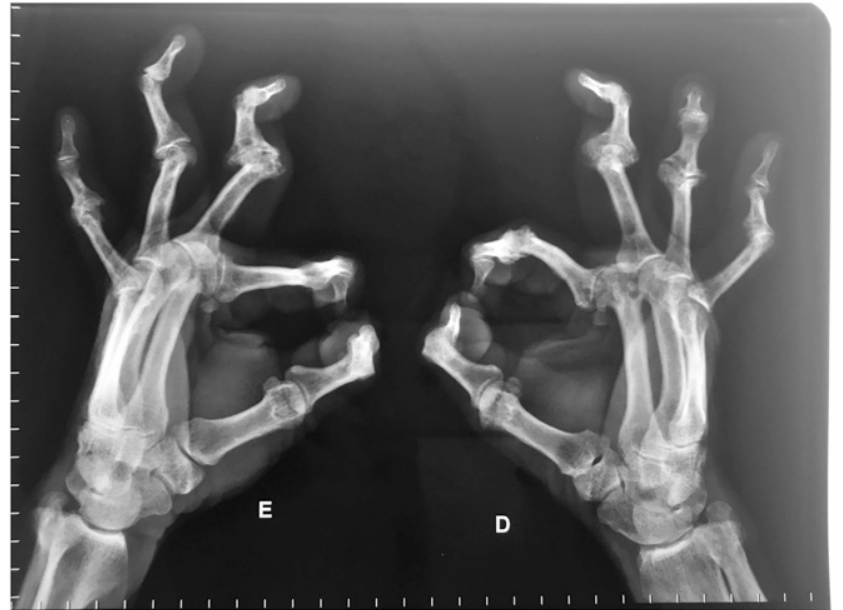

FIGURE 4. "Boutonnière" deformity (fifth right finger) and "swan neck" deformity (third right finger, and third, fourth, and fifth left fingers).

fourth and fifth toe ("boutonnière finger" deformity), were also evident (Figure 6).

\section{DISCUSSION}

Leprosy-related arthritis can be divided into the following groups: 1) neuropathic arthropathy or Charcot's joints, 2) septic arthritis, 3) acute polyarthritis of the leprosy reaction, and 4) chronic arthritis. ${ }^{8}$ Arthritis in leprosy reactions presents acutely, being a symmetrical inflammatory polyarthritis that affects small joints of the hands and feet, similar to RA. ${ }^{8}$

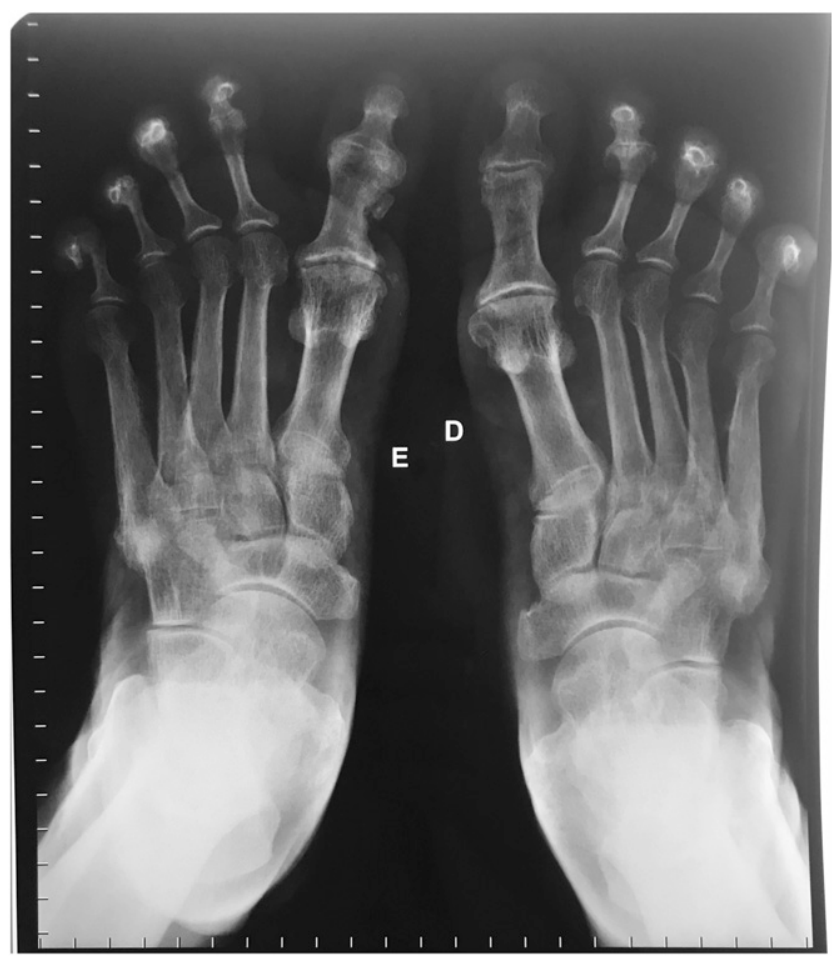

FIGURE 5. Reduction of the metatarsophalangeal joint space of the bilateral hallux and interphalangeal joint, marginal osteophytosis, and subchondral cysts. 


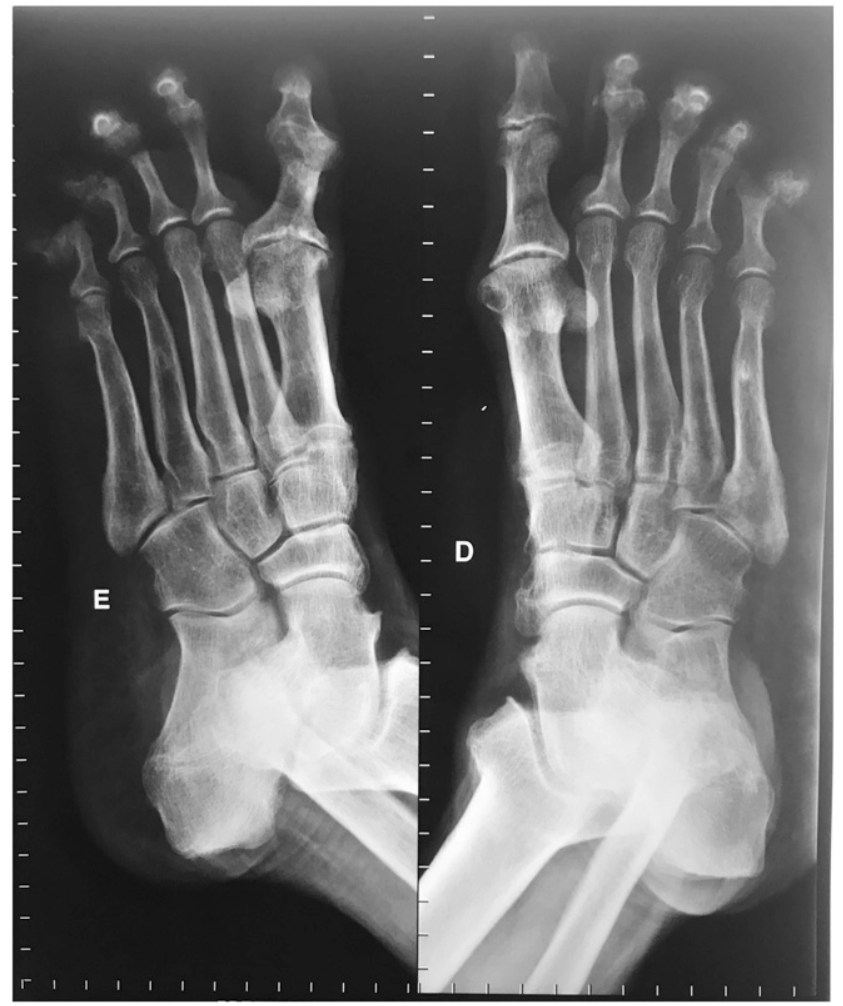

FiguRE 6. Medial phalangeal flexion and hyperextension of the distal phalanges, more evident in the fourth and fifth toes ("boutonnière finger" deformity).

Chronic arthritis not associated with leprosy reactions is a symmetrical polyarthritis, similar to RA of prolonged duration. ${ }^{8}$

Clinical symptoms of arthritis are pain and edema with joint effusion. ${ }^{13}$ The most common radiological changes in patients with inflammatory joint involvement are fusiform edema in soft areas, periarticular porosity and erosions, and narrowing of the joint space. In people affected by leprosy presenting with polyarthritis, differential diagnosis to rule out RA is essential, as indicated in our case by negative tests for rheumatoid factor, C-reactive protein, and antinuclear factor. Also, radiographic changes in RA are usually more pronounced than those observed in leprosy-related arthritis. ${ }^{14}$ Although we could not rule out some age-related arthropathy, the degree of articular alterations in this case was entirely consistent with sequelae of leprosy.

Most cases of leprosy-related arthritis are associated with reactional episodes and, in a large number of patients, arthritis evolves chronically and does not respond to conventional therapy for reactions. ${ }^{15}$ Cossermelli-Messina et al. ${ }^{16}$ described 39 cases of chronic arthritis not associated with leprosy reactions. Although these patients showed considerable relief with anti-leprosy therapy, their arthritis never resolved completely; permanent injury of the joints occurred in some of these patients, mainly in the hands, leading to "swan neck" and "boutonnière" deformities. It is important to highlight that although MDT can be used to treat and cure leprosy patients, it has limited impact on bone alterations that have already occurred. This emphasizes the need for early diagnosis and treatment of the disease to prevent the development of disabling and disfiguring osteoarticular alterations.

Received September 30, 2019. Accepted for publication March 1, 2020.

Published online March 30, 2020.

Authors' addresses: Rachel Bertolani do Espírito Santo, Rachel A. Serafim, and Patrícia Deps, Federal University of Espírito Santo, Vitória, Brazil, E-mails: rabertolani@gmail.com, rachel.serafim@ gmail.com, and patricia.deps@ufes.br. Jurama Barros Gueiros Bitran, Hospital Universitário Cassiano Antônio de Moraes, Federal University of Espírito Santo, Vitória, Brazil, E-mail: jurama.bitran@ gmail.com. Simon M. Collin, Public Health England, London, United Kingdom, E-mail: simon.collin@phe.gov.uk.

\section{REFERENCES}

1. Han XY, Seo YH, Sizer KC, Schoberle T, May GS, Spencer JS, Li W, Nair RG, 2008. A new Mycobacterium species causing diffuse lepromatous leprosy. Am J Clin Pathol 130: 856-864.

2. Eichelmann K, Gonzalez Gonzalez SE, Salas-Alanis JC, OcampoCandiani J, 2013. Leprosy. An update: definition, pathogenesis, classification, diagnosis, and treatment. Actas Dermosifiliogr 104: 554-563.

3. Ankad BS, Halawar RS, 2015. Bone involvement in leprosy: early changes. Radiol Infect Dis 1: 88-89.

4. Yassin A, el Shennawy M, el Enany G, Wassef NF, Shoeb S, 1975. Leprosy of the upper respiratory tract. A clinical bacteriological, histopathological and histochemical study of twenty cases. $J$ Laryngol Otol 89: 505-511.

5. Ridley DS, Jopling WH, 1966. Classification of leprosy according to immunity. A five-group system. Int $J$ Lepr Other Mycobact Dis 34: 255-273.

6. Walker SL, Lockwood DN, 2006. The clinical and immunological features of leprosy. Br Med Bull 77-78: 103-121.

7. Andrade TCPC, Martins TY, Vieira BC, Santiago TM, Soares CT, Barreto JA, 2017. Lepromatous leprosy simulating rheumatoid arthritis - report of a neglected disease. An Bras Dermatol 92: 389-391.

8. Chauhan S, Wakhlu A, Agarwal V, 2010. Arthritis in leprosy. Rheumatology (Oxford) 49: 2237-2242.

9. Chikhalikar AA, Golwalla AF, Shah AB, Hattangadi GS, 1976. Recurrent arthritis: unusual presentation of leprosy. J Postgrad Med 22: 154-156.

10. Fernandes TR, Korinfskin JP, Espindola MM, Corrêa LM, 2014. Arthritis and diagnosis of leprosy: a case report and review of the literature. An Bras Dermatol 89: 323-325.

11. Lele RD, Sainani GS, Sharma KD, 1965. Leprosy presenting as rheumatoid arthritis. J Assoc Physicians India 13: 275-277.

12. Markusse HM, Smelt AH, Teepe RG, 1989. Unusual arthritis: be on the alert for leprosy. Clin Rheumatol 8: 266-268.

13. Slim FJ, Faber WR, Maas $M, 2009$. The role of radiology in nerve function impairment and its musculoskeletal complications in leprosy. Lepr Rev 80: 373-387.

14. Pereira HLA, Ribeiro SLE, Ciconelli RM, da Rocha Correa Fernandes A, 2006. Avaliação por imagem do comprometimento osteoarticular e de nervos periféricos na hanseníase. Rev Bras Reumatol 46: 30-35.

15. Pereira HL, Ribeiro SL, Pennini SN, Sato El, 2009. Leprosy-related joint involvement. Clin Rheumatol 28: 79-84.

16. Cossermelli-Messina W, Festa Neto C, Cossermelli W, 1998. Articular inflammatory manifestations in patients with different forms of leprosy. J Rheumatol 25: 111-119. 